\title{
Development of Acoustic Emission Viscosity Model for Measuring Engine Oil Viscosity Relationship with Engine Oil In-Service Age
}

\author{
Othman Inayatullah ${ }^{1)^{*}}$, Nordin Jamaludin ${ }^{2)}$, Mohd Jailani Mohd Nor ${ }^{2)}$, Yusoff $\mathrm{Ali}^{2)}$ and Fauziah $\mathrm{Mat}^{3)}$ \\ ${ }^{1)}$ School of Manufacturing Engineering, Malaysia Perlis University \\ Alam Pauh Campus 02600 Pauh Perlis, Malaysia \\ ${ }^{2)}$ Department of Mechanical and Material Engineering, Malaysia National University \\ 43600 Bangi Selangor, Malaysia \\ ${ }^{3)}$ School of Mechatronic Engineering, Malaysia Perlis University \\ Alam Pauh Campus 02600 Pauh Perlis, Malaysia \\ *Corresponding author: iothman@unimap.edu.my
}

( Manuscript received 14 December 2009; accepted 18 September 2010; published 31 October 2010 )

\begin{abstract}
Monitoring the viscosity of diesel engine oil is very important as it affects the performance of engines. In this study, the AE signals are applied for measuring the viscosity of engine oil which is affected by the increase of the age of the in-service duration. AE signals are generated in the sliding zone of the piston as well as on the engine oil surface, because the signal is very sensitive to the viscosity of the engine oil. The AE signals can be translated into AE energy by using the Time Domain Analysis. The value of the viscosity will be assessed from the AE energy by applying certain mathematical equations. This study shows that the AE viscosity model is applicable to determine the viscosity of the engine diesel oil.
\end{abstract}

Keywords: acoustic emission, AE energy, viscosity of engine oil, in-service age, AE visco-model

\section{Introduction}

The lubrication systems or engine oil systems can be justifiably credited in the advancement of producing high performances in diesel engines and it can be said that without adequate engine oils and systems for employing them, the diesel engine would quickly cease to function. The most critical component in internal combustion engine is bearings. The bearing surface destroyed quickly when engine operated under engine oil condition. Bearings may be broadly defined as surfaces between which there is relative motion. This motion can be a rotating or linear motion, but in either case, the bearing must allow the motion to get minimum friction as well as support any loads that are present. In a diesel engine, there are three types of bearings which are the guide bearings, the thrust bearings and the journal bearings.

Guide bearings as their name implies, exist to guide a machine component undergoing a length-wise motion. Thus, the cylinder bore is a guide bearing, as are the valve guides. Guide bearings are normally lubricated by either the pressure system or by splash lubrication and they depend mainly on their manufactured characteristics. An engine lubricant which is generally an oil and known commonly as engine oil is derived from crude oil after going through several refining processes.

The engine oil performs several important functions in the engine, among which include lubricating, cooling, sealing, cleaning and protecting against wear and tear and as well as corrosion. The base oil stock alone is not capable of performing all these functions, thus additive agents are used to enhance the performance. Additives fall into three primary functional groups: engine protectors, oil property modifiers and base stock protectors ${ }^{1)}$. The oil property modifiers include pour point depressors, antifoam agents and most importantly the viscosity index improvers.

The parameter that plays a fundamental role in the engine is the viscosity of the oil. It is a known fact that viscosity of oil changes with temperature, shear rate and pressure and in addition the thickness of the generated oil film is usually proportional to the viscosity. But on the other hand, the viscosity of the engine oil changes with the duration of its use. A commonly raised question of an average motorist 
concerns the frequency of having to change the engine oil. Most manufacturers recommend a change of engine oil at intervals of 7,500 miles of normal driving conditions. But, manufacturers differ in their recommendations of the duration for the change of the engine oil and on the other hand; the definition of normal driving conditions is not standardized.

Customarily, the measurement of the viscosity of the engine oil is carried out by using an oil analysis which is by conducting laboratory analysis. Oil analysis is one of the methods to measure the engine oil viscosity directly. Typically, oil analysis implemented by rheology viscometer equipment. The short coming of this analytical method, however, it can only be carried out on engines that are out of service.

In this sort of problem related orientation, the acoustic emission (AE) method with a propagation of elastic waves that run at frequency from $0.1 \mathrm{MHz}$ to 1 $\mathrm{MHz}$ is suitable to be used to measure the estimated value of the viscosity of the engine oil. The elastic waves are generated within or on the surface of a material by certain fundamental processes that define friction, wear and tear in the form of deformations and micro fractures ${ }^{2)}$.

The study of the measurements of these propagating waves is also known as the Stress Wave Analysis, which is possible to be conducted on the surface of the material via an appropriate transducer and acquisition system. AE means the stress waves inside a material which are generated by rapid release of local instabilities. The instabilities or the source mechanisms of AE can be divides in four major groups as dislocation movements, phase transformations, friction mechanisms, crack formation and extension ${ }^{3)}$.

Therefore, through evaluation of the AE activity some insights can be obtained of the behaviour of either solid with solid or solid with fluid of interacting materials in locations which may be prohibitive for other monitoring techniques. This paper explores this potential with reference to the sliding of the piston and the cylinder interface lining covered by engine oil of an in-service diesel engine. In general, this study is based on the friction model ${ }^{4-12)}$ therefore the parametric value of an acoustic emission signal is not directly applicable in monitoring and measuring the viscosity of the engine oil.

With a cause that is problem-oriented, this paper presents a new method which enables acoustic emission signals to be applied in the measurement of the viscosity value of the engine oil. This model is known as AE Viscosity (AEvisco). The development of this model is based on the AE Friction Model and a detailed explanation of the basic Viscosity Theory will be discussed in this paper. The main aim of this study is to reaffirm that the AEvisco model can be used in measuring the viscosity value of the engine oil. With this confirmation, it proves that the following used equation is acceptable.

\section{Development of the AEvisco analytical model}

The AEvisco Analytical Model is an equation issue of two parts which are the AE Friction Model and the Viscosity Theory as mentioned earlier. The development of this model began with the AE Friction Model. This model was developed through pin-on-disk experiments in a dry sliding contact and the following empirical relation of the AE friction energy rate $\left(\dot{E}_{f}\right)$ which is generated from the sliding frictional contact $^{3,5)}$.

In AE Friction Model, $\mathrm{AE}$ friction energy rate is similar to AE energy rate. AE friction energy rate is the sum of the AE friction energy emitted by all events observed per unit time $(\Delta t)$. Sum of the AE friction energy is defined as the area under the squared amplitude of the time domain analysis signal ${ }^{13,14)}$ in Joule and can be expressed as

$$
E_{f}=\int_{0}^{T} v^{2}(t) d t
$$

where $v^{2}(t)$ is the squared amplitude of the time domain analysis signal and $t$ is the specific period of time of the time domain analysis signal. The AE energy carried by the $\mathrm{AE}$ wave converts back and forth between the potential energy of the extra compression or lateral displacement strain of the matter and the kinetic energy of the oscillations of the medium.

In this case, AE signal freed when occurrence of sliding activity between pistons skirt and cylinder liner surface with coated by engine oil. This actually showed that observation of AE signal relatable to interaction between piston and engine oil layer. This is due to free contact between piston skirt and cylinder liner.

In small fragment, the AE friction energy rate can be expressed as

$E_{f}^{Q} \propto\left(\tau_{s} A_{s} v_{s}\right)^{\frac{m}{2}}$

where $\tau_{s}$ is the shear strength of the interfacial layer in $\mathrm{N} / \mathrm{m}^{2}, A_{s}$ is the actual area of contact in $\mathrm{m}^{2}, v_{s}$ is the sliding velocity in $\mathrm{m} / \mathrm{s}$ and $m$ is a constant determined by the material system and the detection equipment. In dry contact, thus can be assumed as $m$ equal $1^{3,5,15)}$.

In equation (2), $\mathrm{AE}$ energy rate directly proportional with shear strength. In dry contact, shear strength referring to sliding contact between solid surfaces. Nevertheless, in non dry contact, shear strength referring to sliding contact between solid surfaces with the fluid or gas layer. In non dry contacts, shear strength actually referring to fluid shear stress. In fluid, shear stress directly proportional with viscosity if others parameters as velocity and the fluid thickness is constant.

In this study, viscosity of engine oil represents the strength of movement resistance ${ }^{16)}$. As lubrication piston skirt is hydrodynamic lubricant, increase of viscosity value cause occurrence of increase coefficient of friction if pressure, lubricating oil, radius and 
velocity thickness constant ${ }^{17)}$. Apart from that, value of engine oil viscosity also influenced the value of piston friction force through shear stress ${ }^{18)}$.

Generally AE signal freed when occurrence of dynamic activity whether on the surface or in media. This dynamic activity formed within two state namely formed inherently and formed by force. Release AE signal not only due to sliding contact between solid with solid but it can also be released through sliding contact between solid with fluid or sliding contact between solid with gas. In monitoring lubrication viscosity of industry bearing, AE signal released through sliding contact between solid with fluid ${ }^{13)}$. In previous study, the AE energy's directly proportional with viscosity ${ }^{13)}$.

Concerning Equation (2), either the increasing sliding velocity or with stronger interfacial layers, the average frequency and amplitude of $\mathrm{AE}$ events is increased. This increase produces a non-linear increase in the energy detected by the AE monitoring equipment. A complex contact situation is the sum of the small fragment contacts illustrated in Fig. 1 and the total AE friction energy $\left(\dot{E}_{f T}\right)$ which can be expressed as $\left.{ }^{15}\right)$

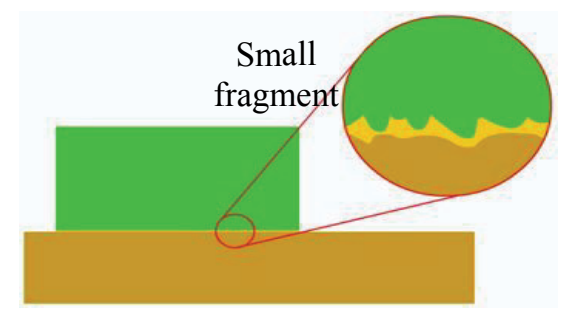

Fig. 1 In the complex contact situation is the sum of the small fragment contact

$$
E_{f T}^{Q}=\int_{A} a_{f}\left(\tau_{s} A_{s} v_{s}\right)^{\frac{m}{2}} d A=a_{f} \int_{A}\left(F_{f} v_{s}\right)^{\frac{m}{2}} d A
$$

where $a_{f}$ is a proportionality constant. In this case, the $a_{f}$ is decidedly non-linear and must be expressed as a function of the cylinder block thickness. Through Equation (3), the total AE friction energy $\left(\dot{E}_{f T}\right)$ can be expressed as

$$
E_{f T}=a_{f}(\tau v)^{\frac{m}{2}} \frac{A^{\frac{m}{2}+1}}{\frac{m}{2}+1}
$$

$A$ is the sum of the small fragment contact area in $\mathrm{m}^{2}$ and $F_{f}$ is the frictional force in N. In Equation (4), the $\tau$ and $v$ value assuming equal to $\tau$ and $v$ in small fragment.

In the simultaneous overall contact, total contact area in non-dry contact cannot be neglected and also the value $m$ cannot be assumed as 1 . Typically the AE energy rate is depend on the shear stress, contact area and also the sliding velocity. In this study, the value $m$ can be projected more than 1 .

Concerning Equation (4), the AE friction energy can be stated as

$$
E_{f T}=a_{f}(\tau v)^{\frac{m}{2}} \frac{A^{\frac{m}{2}+1}}{\frac{m}{2}+1} t
$$

where $t$ is the specific period of time of the time domain analysis signal. Through Equation (5), shear stress can be stated as

$\tau=\frac{1}{v}\left[\frac{E_{f T}\left(\frac{m}{2}+1\right)}{a_{f} t A^{\frac{m}{2}+1}}\right]^{2 / m}$

where $A$ is the area of the contact and can be formulated as

$$
A=\pi B h
$$

where $B$ is the bore diameter and $h$ is the high of the piston skirt.

Normally in engine condition monitoring study by AE technology give different result base on the location of the AE sensor. If the AE sensor located at $\mathrm{TDC}$, the AE signal related to cylinder pressure in combustion area ${ }^{19}$. But when the AE sensor located at the stroke of the engine, the AE signal can be related with behaviour of interaction ring/cylinder liner ${ }^{20)}$. Based on that, for this study, the AE sensor located below than $\mathrm{BDC}^{21)}$. In this study, the $\mathrm{AE}$ signal is generate when the sliding activates between piston skirt and a cylinder liner with the oil film as the medium ${ }^{21)}$. $v_{s}$ is the velocity of the piston and can be formulated as

$$
v=2 S N_{s}
$$

where $S$ is the length of stroke and $N_{s}$ is the rotation per second.

In the Newtonian fluid, the shear stress is shown as

$$
\tau=\eta \frac{v}{c}
$$

where $\eta$ is the viscosity and $c$ is the thickness of the oil film in $m$ and $v$ is the velocity. The equation applied in Equation (9) through the Newton Equation and therefore the viscosity can be written as

$\eta=\tau \frac{c}{v}$

The value of the thickness of the oil film can be assumed as the clearance between the piston skirt and the cylinder liner. The AEvisco $\left(\eta_{A E}\right)$ can be formulated by replacing the $\tau$ in Equation (10) with Equation (6) as 
$\eta_{A E}=\frac{c}{v^{2}}\left[\frac{E_{f T}\left(\frac{m}{2}\right)}{a_{f} t A^{\frac{m}{2}+1}}\right]^{2 / m}$

where, $E_{f t}$ in $\mathrm{J}, t$ in sec, $A$ in $\mathrm{m}^{2}, c$ in $\mathrm{m}$ and $v$ in $\mathrm{m} / \mathrm{s} . m$ and $a_{f}$ is the constant factor. In this study, the $m$ and $a_{f}$ value are assumed not related the dimension because Equation (11) based on an empirical equation. By knowing the value of the AE energy, the viscosity of engine oil can be presupposed by using Equation (11).

\section{Experiment apparatus}

This experiment was carried out on a one-cylinder, four-stroke, $1000 \mathrm{rpm}$, horizontal, water-cooled diesel engine with the range of specifications given in Table 1. The characteristics of the engine oil used in this experiment are given in Table 2.

Table 1 Engine specifications

\begin{tabular}{ll}
\hline Bore & $85.0 \mathrm{~mm}$ \\
Stroke & $87.0 \mathrm{~mm}$ \\
Displacement & 0.493 \\
Compression Ratio & 17.9 \\
Engine Oil Quantity & $2.2 \mathrm{~L}$ \\
Piston Diameter & $84.887 \mathrm{~mm}$ \\
Piston Length & $84.6 \mathrm{~mm}$ \\
Piston Skirt & $34.0 \mathrm{~mm}$ \\
Max In-Service Age & 100 hours \\
\hline
\end{tabular}

Table 2 Engine oil characterises SAE 40

\begin{tabular}{lcc}
\hline & Sample & Sample \\
& A & B \\
\cline { 2 - 3 } Density at $15^{\circ} \mathrm{C}\left(\mathrm{kg} / \mathrm{m}^{3}\right)$ & 897.1 & 900.0 \\
Pour Point $\left({ }^{\circ} \mathrm{C}\right)$ & -6 & -10 \\
Flash Ponit $\left({ }^{\circ} \mathrm{C}\right)$ & 256 & 230 \\
Kinematic Viscosity $\left(\mathrm{mm}^{2} / \mathrm{s}\right)$ & & \\
$\quad 40^{\circ} \mathrm{C}$ & 160.8 & 155 \\
$100^{\circ} \mathrm{C}$ & 15.2 & 15.5 \\
Viscosity Index & 96 & 100 \\
\hline
\end{tabular}

Fig. 2 Shows the Data Acquisition System (DAQ) used for a small diesel engine. Physical Acoustic Corporation (PAC) Wide Band (WD) sensor was coupled to the engine surface by applying thin layers of vacuum grease. The location of the sensor is below the Bottom Dead Centre (BDC). Signal amplification and band-pass filtering $(100 \mathrm{kHz}$ to $1 \mathrm{MHz})$ are provided by PAC $1220 \mathrm{~A}$ pre-amplifiers with gains of $40 \mathrm{~dB}$, as necessary through a signal conditioning unit. Raw data is acquired at sampling rates of $5 \mathrm{MHz}$ via single channel PAC DiSP with AEwin ${ }^{T M}$ ver1.30 software.

In this work, the engine oil temperature is locked at $45{ }^{\circ} \mathrm{C}$ and $55^{\circ} \mathrm{C}$ and after every 10 hours up to 100 hours from 0 hour, the $\mathrm{AE}$ is measured. By using the oil analysis, the real viscosity of the engine oil is recorded.
In the oil analysis, the viscosity values adopted at temperatures of the $\mathrm{AE}$ measurement temperatures which are $35{ }^{\circ} \mathrm{C}$ and $60{ }^{\circ} \mathrm{C}$. The values of viscosity at $35^{\circ} \mathrm{C}$ and $60{ }^{\circ} \mathrm{C}$ are applied as reference values in finding the values of viscosity by ASTM D341 software and it is known as ASTM analysis in this work $^{22)}$. The ASTM D341 software or ASTM D341 model is based on measurement of engine oil viscosity through ASTM D341 analytical method ${ }^{22)}$.

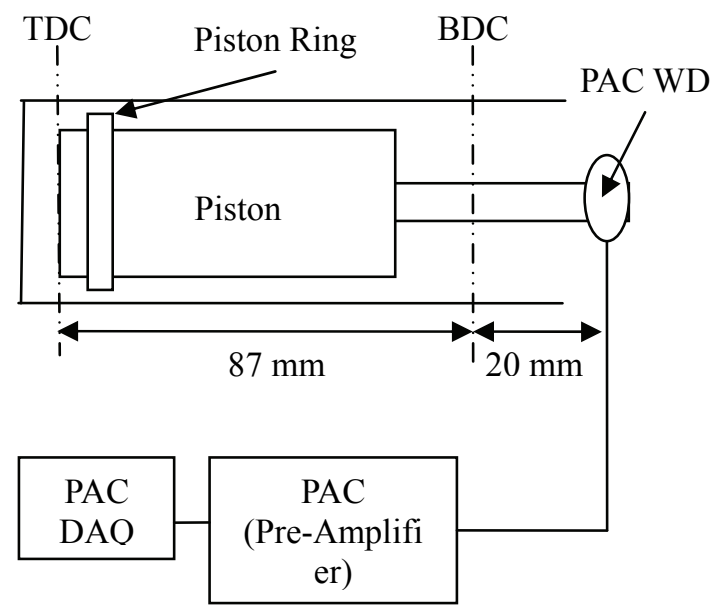

Fig. 2 An outline of data acquisition chain for a small diesel engine

Generally, ASTM equation based on Walther equation's issue shown in Equation (12) ${ }^{23)}$. Base on Equation (12), Spotts et al. (2004) develop the ASTM D341 software and it is shown in Fig 3. In this study, the viscosity of engine oil based ASTM D341 model wasn't

considerate to the density of the engine oil. It's shown clearly in Fig 3, where the result of viscosity based to reverences viscosity as have say before ${ }^{22)}$. The engine oil sample applies in this study is marked as $\mathrm{A} 45^{\circ} \mathrm{C}, \mathrm{A}$ $55^{\circ} \mathrm{C}, \mathrm{B} 45^{\circ} \mathrm{C}$ and B $55^{\circ} \mathrm{C}$.

\begin{tabular}{|c|c|c|c|}
\hline \multicolumn{4}{|c|}{ Module 8-2 } \\
\hline \multicolumn{4}{|c|}{ Viscosity versus Temperature for any oil } \\
\hline \multicolumn{4}{|c|}{$\begin{array}{l}\text { This module is equivalent to using ASTM Chart D } 341 \text {. } \\
\text { Valid viscosity range: } 0.21 \leq \mu \leq 2 \times 10^{7} \text { centistokes. } \\
\text { Valid temperature range is between the cloud point } \\
\text { and the initial boiling point for the oil. }\end{array}$} \\
\hline \multicolumn{4}{|c|}{$\begin{array}{l}\text { Input two sets of temperature and viscosity values } \\
\text { to define the line on the ASTM Chart D } 341 \text {. }\end{array}$} \\
\hline$T_{l}\left({ }^{\circ} \mathrm{C}\right)=$ & 35 & $\operatorname{deg} \mathrm{C}$ & Oil temperature $_{1}$ \\
\hline$\mu_{1}=$ & 105.71 & MPa sec & Absolute Viscosity at $T_{1}$ \\
\hline$T_{2}\left({ }^{\circ} \mathrm{C}\right)=$ & 60 & $\operatorname{deg} \mathrm{C}$ & Oil temperature $_{2}$ \\
\hline$\mu_{2}=$ & 9.429 & Mpa sec & Absolute Viscosity at T1 \\
\hline \multicolumn{4}{|c|}{ Specify the temperature, find the viscosity. } \\
\hline$T\left({ }^{\circ} \mathrm{C}\right)=$ & 82.00 & $\operatorname{deg} \mathrm{C}$ & Oil temperature \\
\hline$\mu=$ & 2.98 & Mpa sec & Absolute Viscosity found \\
\hline
\end{tabular}

Fig. 3 ASTM D341 module software 


$$
\log \log (v+0.7)=A-B \log T
$$

where $v$ is kinematic viscosity, $A$ and $B$ is the constant parameter and $T$ is temperature in $\mathrm{K}$.

Typically, the AE signal can be recorded, when occurrence of interaction between piston, engine oil and cylinder liner. The signal displayed in time domain form. By MATLAB software, the AE signal can be converting to AE energy value in time domain analysis. In this study, AE energy was focus parameter.

\section{Results and discussion}

In this study, the observation of AE signal shown in burst type signal. The phenomena are due to the release of stress wave occurring in short periods. This is different with the dry-contact behaviour in friction model $^{13,24)}$. This actually caused by movement of piston and interaction between piston surface with engine oil and cylinder liner surface shaped injection. That way the AE signal observation was in short time. This contrasts with journal bearing. It is shown in Fig. 4.

By Time Domain Analysis, the AE signal in this study generally involves the total AE friction energy $\left(E_{f T}\right)$ as shown in Table 3. From the study, all the samples shown the AE energy basically decreases

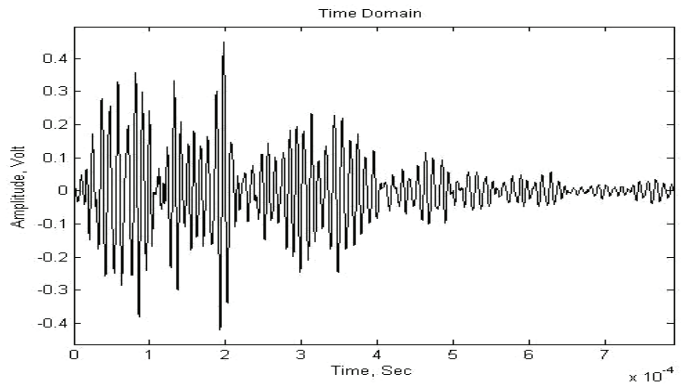

Fig. 4 AE signal shown as the burst type with time of observation is $0.0007894 \mathrm{sec}$

Table 3 Total AE friction energy from AE signal by time domain analysis

\begin{tabular}{|c|c|c|c|c|}
\hline $\begin{array}{c}\text { In-Service } \\
\text { Age } \\
\text { (Hour) }\end{array}$ & $\begin{array}{c}\text { Sample } \\
\mathrm{A} \\
45^{\circ} \mathrm{C} \\
\left(10^{-5} \mathrm{~J}\right)\end{array}$ & $\begin{array}{c}\text { Sample } \\
\mathrm{A} \\
55^{\circ} \mathrm{C} \\
\left(10^{-5} \mathrm{~J}\right)\end{array}$ & $\begin{array}{c}\text { Sample } \\
\mathrm{B} \\
45^{\circ} \mathrm{C} \\
\left(10^{-5} \mathrm{~J}\right)\end{array}$ & $\begin{array}{c}\text { Sample } \\
\mathrm{B} \\
55^{\circ} \mathrm{C} \\
\left(10^{-5} \mathrm{~J}\right)\end{array}$ \\
\hline 0 & 3.481 & 2.649 & 3.423 & 2.618 \\
\hline 10 & 3.447 & 2.637 & 3.388 & 2.590 \\
\hline 20 & 3.440 & 2.603 & 3.353 & 2.562 \\
\hline 30 & 3.426 & 2.599 & 3.321 & 2.536 \\
\hline 40 & 3.364 & 2.567 & 3.284 & 2.501 \\
\hline 50 & 3.320 & 2.538 & 3.254 & 2.479 \\
\hline 60 & 3.289 & 2.520 & 3.201 & 2.452 \\
\hline 70 & 3.259 & 2.482 & 3.184 & 2.444 \\
\hline 80 & 3.246 & 2.464 & 3.140 & 2.406 \\
\hline 90 & 3.227 & 2.445 & 3.090 & 2.371 \\
\hline 100 & 3.204 & 2.413 & 3.068 & 2.352 \\
\hline
\end{tabular}

constantly when in-service age increasing.

Due to that reason the AE analysis cannot be used as a direct monitored behaviour of the viscosity of engine oil especially in medium temperatures. In this study, value of $m$ can be assumed as 1.35 and value of $a_{f}$ assumed as 0.431402. The value of $m$ and $a_{f}$ achieved through simultaneous equation method by Equation (11). The value of viscosity and AE energy at $35^{\circ} \mathrm{C}$ for engine oil sample $\mathrm{A}$ and $\mathrm{B}$ as displayed in Table 4 was used to determine the value of $m$ and $\mathrm{a}_{f}$.

By Equation (11), the AEvisco $\left(\eta_{A E}\right)$ can be calculated based the value of total AE friction energy. It is given in Table 5 .

Table 4 AE energy and viscosity at $35^{\circ} \mathrm{C}$

\begin{tabular}{ccc}
\hline Sample & $\begin{array}{c}\text { AE energy } \\
\left(\mathrm{e}^{-5} \mathrm{~J}\right)\end{array}$ & $\begin{array}{c}\text { Viscosity } \\
(\mathrm{Pa} . \mathrm{s})\end{array}$ \\
\hline $\mathrm{A}$ & 0.1146 & 0.0766 \\
$\mathrm{~B}$ & 0.1131 & 0.0761 \\
\hline
\end{tabular}

Table 5 AEvisco $\left(\eta_{A E}\right)$

\begin{tabular}{|c|c|c|c|c|}
\hline $\begin{array}{c}\text { In-Service } \\
\text { Age } \\
\text { (Hour) }\end{array}$ & $\begin{array}{c}\text { Sample } \\
\text { A } \\
45^{\circ} \mathrm{C} \\
(\text { Pa.s })\end{array}$ & $\begin{array}{c}\text { Sample } \\
\text { A } \\
55^{\circ} \mathrm{C} \\
(\mathrm{Pa} . \mathrm{s})\end{array}$ & $\begin{array}{c}\text { Sample } \\
\text { B } \\
45^{\circ} \mathrm{C} \\
(\mathrm{Pa} . \mathrm{s})\end{array}$ & $\begin{array}{c}\text { Sample } \\
\mathrm{B} \\
55^{\circ} \mathrm{C} \\
(\text { Pa.s })\end{array}$ \\
\hline 0 & 0.1146 & 0.0766 & 0.1120 & 0.0753 \\
\hline 10 & 0.1131 & 0.0761 & 0.1103 & 0.0741 \\
\hline 20 & 0.1124 & 0.0746 & 0.1086 & 0.0729 \\
\hline 30 & 0.1121 & 0.0744 & 0.1070 & 0.0718 \\
\hline 40 & 0.1093 & 0.0731 & 0.1053 & 0.0703 \\
\hline 50 & 0.1072 & 0.0719 & 0.1039 & 0.0694 \\
\hline 60 & 0.1052 & 0.0711 & 0.1014 & 0.0683 \\
\hline 70 & 0.1042 & 0.0695 & 0.1006 & 0.0680 \\
\hline 80 & 0.1034 & 0.0688 & 0.0985 & 0.0664 \\
\hline 90 & 0.1028 & 0.0680 & 0.0962 & 0.0650 \\
\hline 100 & 0.1015 & 0.0667 & 0.0952 & 0.0642 \\
\hline
\end{tabular}

Table 6 Engine oil viscosity by oil analysis

\begin{tabular}{|c|c|c|c|c|}
\hline $\begin{array}{c}\text { In-Service } \\
\text { Age } \\
\text { (Hour) }\end{array}$ & $\begin{array}{c}\text { Sample } \\
\text { A } \\
45^{\circ} \mathrm{C} \\
(\mathrm{Pa} . \mathrm{s})\end{array}$ & $\begin{array}{c}\text { Sample } \\
\text { A } \\
55^{\circ} \mathrm{C} \\
(\mathrm{Pa} . \mathrm{s})\end{array}$ & $\begin{array}{c}\text { Sample } \\
\text { B } \\
45^{\circ} \mathrm{C} \\
(\text { Pa.s })\end{array}$ & $\begin{array}{c}\text { Sample } \\
\mathrm{B} \\
55^{\circ} \mathrm{C} \\
\text { (Pa.s) }\end{array}$ \\
\hline 0 & 0.1148 & 0.0766 & 0.1116 & 0.0752 \\
\hline 10 & 0.1131 & 0.0758 & 0.1099 & 0.0741 \\
\hline 20 & 0.1128 & 0.0748 & 0.1083 & 0.0726 \\
\hline 30 & 0.1121 & 0.0745 & 0.1069 & 0.0716 \\
\hline 40 & 0.1091 & 0.0732 & 0.1051 & 0.0702 \\
\hline 50 & 0.1070 & 0.0718 & 0.1033 & 0.0696 \\
\hline 60 & 0.1055 & 0.0708 & 0.1015 & 0.0681 \\
\hline 70 & 0.1041 & 0.0692 & 0.1009 & 0.0677 \\
\hline 80 & 0.1035 & 0.0689 & 0.0987 & 0.0665 \\
\hline 90 & 0.1026 & 0.0679 & 0.0963 & 0.0653 \\
\hline 100 & 0.1015 & 0.0669 & 0.0949 & 0.0640 \\
\hline
\end{tabular}


Table 7 Viscosity from ASTM D341 software

\begin{tabular}{|c|c|c|c|c|}
\hline $\begin{array}{c}\text { In-Service } \\
\text { Age } \\
\text { (Hour) }\end{array}$ & $\begin{array}{c}\text { Sample } \\
\text { A } \\
45^{\circ} \mathrm{C} \\
(\text { Pa.s })\end{array}$ & $\begin{array}{c}\text { Sample } \\
\text { A } \\
55^{\circ} \mathrm{C} \\
(\mathrm{Pa} . \mathrm{s})\end{array}$ & $\begin{array}{c}\text { Sample } \\
\text { B } \\
45^{\circ} \mathrm{C} \\
(\mathrm{Pa} . \mathrm{s})\end{array}$ & $\begin{array}{c}\text { Sample } \\
\text { B } \\
55^{\circ} \mathrm{C} \\
(\mathrm{Pa} . \mathrm{s})\end{array}$ \\
\hline 0 & 0.1109 & 0.0750 & 0.1079 & 0.0737 \\
\hline 10 & 0.1087 & 0.0730 & 0.1062 & 0.0725 \\
\hline 20 & 0.1073 & 0.0714 & 0.1043 & 0.0713 \\
\hline 30 & 0.1061 & 0.0703 & 0.1031 & 0.0702 \\
\hline 40 & 0.1041 & 0.0696 & 0.1015 & 0.0694 \\
\hline 50 & 0.1020 & 0.0684 & 0.0997 & 0.0680 \\
\hline 60 & 0.1004 & 0.0669 & 0.0982 & 0.0672 \\
\hline 70 & 0.0986 & 0.0656 & 0.0965 & 0.0658 \\
\hline 80 & 0.0976 & 0.0645 & 0.0953 & 0.0652 \\
\hline 90 & 0.0964 & 0.0638 & 0.0936 & 0.0640 \\
\hline 100 & 0.0946 & 0.0624 & 0.0917 & 0.0627 \\
\hline
\end{tabular}

Based on Table 5, the AEvisco $\left(\eta_{A E}\right)$ consistently decreases when there is an increase of in-service age. The AEvisco $\left(\eta_{A E}\right)$ experience reduction when temperature increases. This is common phenomenon for hydrodynamic lubricant. Apart from that, studies of oil analysis shown the engine oil viscosity decreases when in-service age increasing. This was shown in Table 6.

To compare, viscosity study also done with ASTM D 341 software. This comparison is important to see the accuracy between viscosity from ASTM D 341 software $\left(\eta_{A S T M}\right)$ and AEvisco $\left(\eta_{A E}\right)$. From the survey results, the viscosity values declined similar to the viscosity of oil analysis. This was shown in Table 7. In Table 7 , the viscosity value $\left(\eta_{A S T M}\right)$ for sample A 55 ${ }^{\circ} \mathrm{C}$ and sample B $55^{\circ} \mathrm{C}$ had shown close each other. In other part, the Table 6 and Fig. 7 had shown the early 50 hours in-service age, the viscosity value for sample A $55^{\circ} \mathrm{C}$ higher than sample B $55^{\circ} \mathrm{C}$. This unexpected phenomena happening because the ASTM D 341 software is based on $100 \%$ Newtonian fluid behaviour $^{23)}$.

By corresponding value of the engine oil viscosity measured by oil analysis, the AEvisco is measured and correlated. From the result, AEvisco showed nearly identical to real engine oil viscosity. It is clear from Fig. 5 that the viscosity of the engine oil in both tests is more or less the same. The error between viscosities by $\mathrm{AE}$ analysis and oil analysis is $-0.49 \%$ to $0.55 \%$. It is lower than error between viscosities by ASTM analysis and oil analysis. The error of ASTM analysis vs. oil analysis is $-5.69 \%$ to $-1.14 \%$. Normally, the accurate of $\mathrm{AE}$ analysis viscosity are based on the AE energy. In other hand, the real AE energy base on the real engine oil viscosity. It is different with ASTM viscosity where ASTM viscosity data come out from Walther equation as Equation (12). That means the ASTM viscosity base on the logarithm equation.

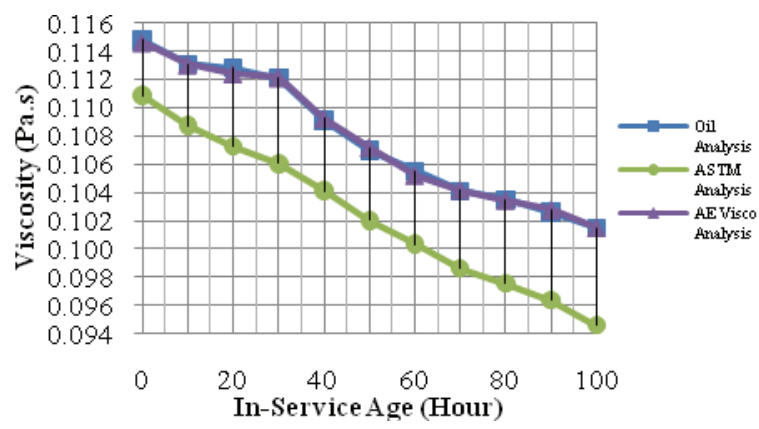

(a)

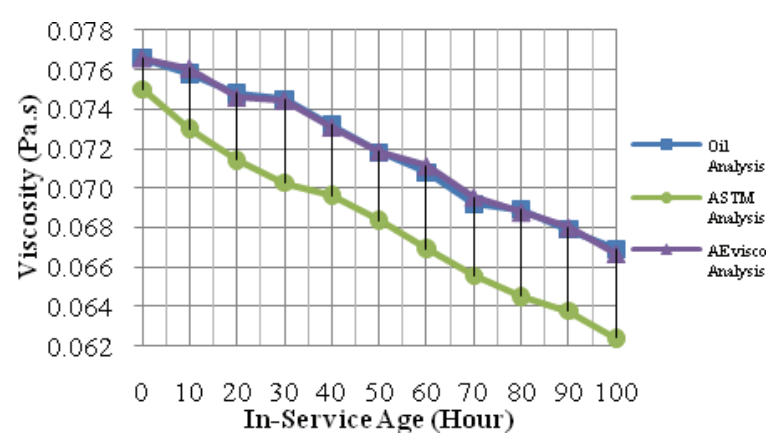

(b)

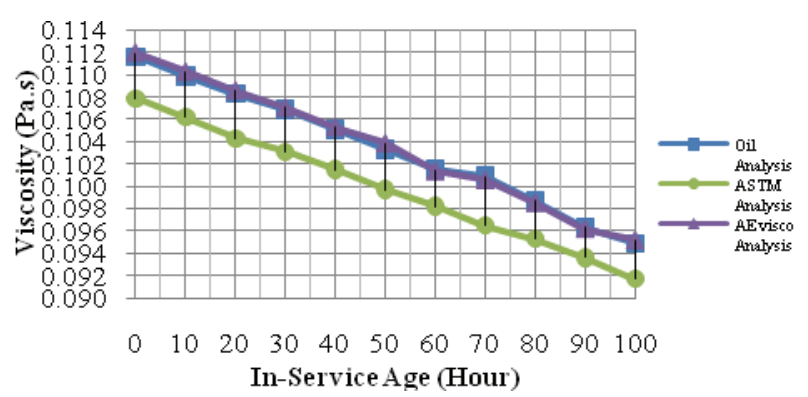

(c)

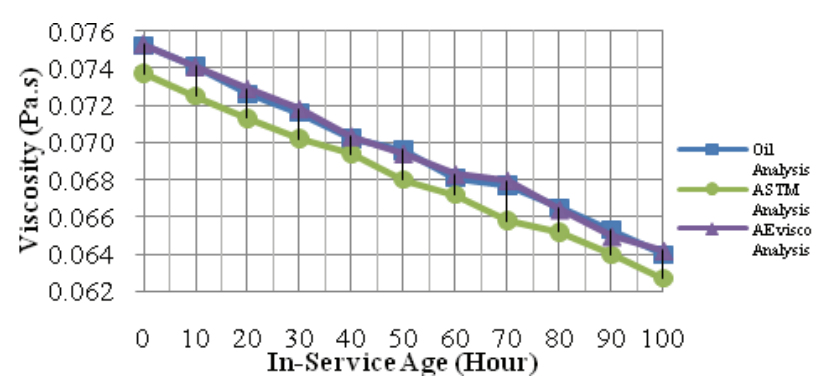

(d)

Fig. 5 Comparisons of engine oil viscosity among the four analyses: (a) Sample A $45^{\circ} \mathrm{C}$ (b) Sample A $55^{\circ} \mathrm{C}$ (c) Sample B $45^{\circ} \mathrm{C}$ and (d) Sample B $55^{\circ} \mathrm{C}$

\section{Conslusion}

It has been demonstrated through a series of experiment results that AEvisco by AE technology tend to be a promising technique for determining and estimating the diesel engine oil. The piston skirt/liner 
interaction has been established as a source of $\mathrm{AE}$ activity and is related to the viscosity of the engine oil. From the AE energy, the AEvisco obtained through the new mathematical model. The development of $\mathrm{AE}$ viscosity model is used to determine the viscosity of the engine oil by AE energy. It is more accurate than ASTM analysis. In this work, it is shown that the viscosity of the engine oil also depends on the in-service age as well as temperature and pressure factors.

By using Equation (11), based on the AE energy, the viscosity is known. Therefore, AE technology can be used as a measurement tool in order to predict the viscosity of the engine oil by the on-line measurement. These equations are shown in their respective figures. It is possible to determine the viscosity of the engine oil directly by substituting the AE energy propagation from the duration of the engine run in.

\section{References}

[1] SAE J357, "Physical and Chemical Properties of Engine Oil," Society of Automotive Engineers, Warrendale, 1999.

[2] Miller, R. K., "Non-Destructive Testing Handbook vol. 5- Acoustic Emission," American Society for Non-Destructive Testing, Columbus, 1987.

[3] Miettien, J. "Condition Monitoring of Grease Lubricated Rolling Bearings by Acoustic Emission Measurements," PhD Tesis, Tampere, 2000.

[4] Boness, R. J. and McBride, S. L., "Adhesive and Abrasive Wear Studies Using Acoustic Emission Techniques," Wear, 149, 1-2, 1991, 41-53.

[5] Jiaa, C. L. and Dornfeld, D. A., "Experimental Studies of Sliding Friction and Wear via Acoustic Emission Signal Analysis," Wear, 139, 2, 1990, 403-423.

[6] Mechefske, C. K. and Sun G., "Monitoring Sliding Wear Using Acoustic Emission," Proc. of the $14^{\text {th }}$ Int. Conference on Condition Monitoring and Diagnostic Engineering Management, (COMADEM), Manchester, 2001, 57-65.

[7] Price, E. D., Lees, A. W. and Friswell, M. I., "Detection of Severe Sliding and Pitting Fatigue Wear Regimes through the use of Broadband Acoustic Emission," Proc. IMechE, Part J: Eng Tribol, 219, 2, 2005, 85-98.

[8] Shuster, M., Combs, D., Karrip, K. and Burek, D., "Piston Ring Cylinder Liner Scuffing Phenomenon Studies Using Acoustic Emission Technique," Proc. of the CEC/SAE Spring Fuel $\&$ Lubricants Meeting and Exposition, Paris, 2000, 901-913.

[9] Kita, T., Kogure, K., Mitsuya, Y. and Nakanishi, T., "New Method of Detecting Contact between Floating-Head and Disk," IEEE Transactions on Magetics, 16, 5, 1980, 873-875.
[10] Khurshudov, A. G. and Talke, F. E., "A Study of Subambient Pressure Tri-Pad Sliders Using Acoustic Emission," ASME Journal of Tribology, 1, 120, 1, 1998, 54-59.

[11] Ravikiran, A., Liew, T. and Low, T. S., "Effect of Disk Acceleration on the Generation of Acoustic Emission Signal at the Head-Disk Interface," Journal of Applied Physics, 85, 8, 1999, 5612-5614.

[12] Tanaka, H., Yanemura, S. and Tokisue, H., "Slider Dynamics during Continuous Contact with Textured and Smooth Disks in Ultra Low Flying Height," IEEE Transactions on Magnetics, 37, 2, 2001, 906-911.

[13] Jamaludin, N., "Monitoring Low Speed Rolling Element Bearing Using Stress Wave Technique," PhD Tesis, Cranfield, 2000.

[14] Hardy, H. R., "Acoustic Emission/Microseismic Activity: Volume 1: Principles, Techniques and Geotechnical Applications," A. A. Balkema Publishers, Netherlands, 2003.

[15] Mullins, W. M., Irwin, R. D., Malas, J. C. and Venugopal, S., "Examination of the use of Acoustic Emission for Monitoring Metal Forging Process: A Study Using Simulation Techniques," Scripta Materialia, 36, 9, 1997, 967-974.

[16] Rosli, H., “Car Engine," UTM \& DBP, Sekudai \& Kuala Lumpur, 1996. (in Malay)

[17] Stone, R. and Ball, J. K., "Automotive Engineering Fundamentals,” SAE, USA, 2004.

[18] Pulkrabek, W. W., "Engineering Fundamentals of the Internal Combustion Engine $2^{\text {nd }}$ ed," Pearson Prentice Hall, New Jersey, 2004.

[19] El-Ghamry, M. H., Reuben, R. L., Steel, J. A. and Fog, T. L., "Indirect Measurement of Cylinder Pressure from Diesel Engines Using Acoustic Emission," Mechanical System and Signal Processing Journal, 19, 4, 2005, 751-765.

[20] Dougles, R. M., Steel, J. A. and Reuben, R. L., “A Study of the Tribological Behaviour of Piston Ring/Cylinder Liner Interaction in Diesel Engines Using Acoustic Emission," Tribology International, 39, 2006, 1634-1642.

[21] Inayatullah, O., Nor, M. J. M., Jamaludin, N. dan Mohamad, T. I., "Determine the Location of Acoustic Emission Sensor on Engine Diesel for Monitoring the Viscosity of the Lubricant," Technology Journal, 49, A, 2008, 19-38. (in Malay)

[22] Spotts, M. F., Shoup, T. E. and Hornberger, L. E., "Design of Machine Elements,"Pearson Prentice Hall, USA, 2004.

[23] Briant, T., Denis, J. and Parc, G., "Rheological Properties of Lubricants," Technip, France, 1989.

[24] Balerston, H. L., "The Detection of Incipient Failure in Bearings," Materials Evaluation, 27, 1969, 121-128. 